\title{
PARAMETRIC STUDY ON THE FIRE RESISTANCE OF STEEL COLUMNS WITH COLD-FORMED LIPPED CHANNEL SECTIONS
}

\author{
Flávio Arrais ${ }^{\mathrm{a}}$, Nuno Lopes ${ }^{\mathrm{a}}$, Paulo Vila Real ${ }^{\mathrm{a}}$ \\ ${ }^{a}$ RISCO - Civil Engineering Department, University of Aveiro, Portugal
}

\begin{abstract}
Steel structural elements with cold-formed thin-walled sections are becoming increasingly common in buildings due to their lightness and ability to support large spans. In these members, local, distortional and global instabilities are important common failure modes. At high temperatures, these instability phenomena are intensified. This paper presents a numerical study on the behaviour of columns with cold-formed C-sections in case of fire when subjected to compression. A parametric study, considering different steel grades, temperatures and different cross-sections with different slendernesses, is presented. Comparisons are also made between the numerical results and analytical design rules, such as the EN1993-1-2, using its Annex E or its French National Annex, where a different constitutive law is recommended for cold-formed profiles. It is possible to conclude that the simple calculation rules are on the safe side but sometimes too conservative.
\end{abstract}

Keywords: steel, cold-formed, columns, temperature, Eurocode 3

\section{INTRODUCTION}

The cold-formed steel profiles can be applied to almost all existing building typologies. The use of these profiles in construction began around 1850 in the United States and United Kingdom. However, they were not widely used in buildings until 1940 (ASRO, 2008). The cold-formed profiles are commonly used in buildings due to its lightness and ability to support large spans, being quite common as roof or wall support elements (Silvestre et al., 2010a).

The structural steel elements with thin-walled cold-formed sections, subjected to axial compression, are characterized by being able to have the possibility of failure modes occurrence such as local, distortional and global buckling. These instability phenomena and their influence on the ultimate strength at room temperature have been widely studied (Camotim et al., 2007 and Silvestre et al., 2010b). However, the behaviour of these cold-formed steel elements in fire has only recently started to receive more attention (Shahbazian et al., 2011; Arrais, 2012; Laim, 2013; Gunalan et al., 2015). In fact, the fire resistance evaluation of cold-formed profiles has a major role in the resistance of these elements. The thin walls of these profiles, together with the steel's high thermal conductivity, are the reason for the great loss of strength and stiffness of these structural elements.

The fire resistance analysis of columns can be performed using calculation programs with various complexity levels, ranging from those based on simplified methods defined in the Eurocodes, to more complex ones with nonlinear analysis, based on the finite element method and included in the designated advanced calculation methods, as referred in the Eurocodes.

The fire resistance of buildings structures with thin-walled profiles has been calculated using advanced methods with finite element programs that consider the local buckling (e.g. with shell elements). These methods are not easily accessible to designers who regular design cold-formed steel profiles based on prescriptions of Eurocode 3 (EC3).

In this paper, an extensive parametric study of simply supported members with cold-formed lipped channel sections (C) in case of fire when subjected to compression is presented, regarding different cross-section slendernesses, steel grades, and temperatures, in order to validate those design rules.

The numerical results are compared with the design prescriptions of Part 1-2 of EC3 (CEN, 2005). Moreover, the French National Annex (FN Annex) of this Eurocode part (CEN, 2007) proposes the use of different design formulae and different steel constitutive law for cold-formed profiles at elevated temperatures, which is also analysed and applied in this work. 
The different instability modes and corresponding critical loads for these elements were analysed using the software CUFSM (developed at Johns Hopkins university in the United States) (Schafer et al., 2006) and CAST3M (developed at French Atomic Energy Commission) (CAST3M, 2012). The local, distortional and global instability modes obtained in CAST3M were used to define the geometrical imperfection shapes by applying the interface with SAFIR, RUBY (developed at the University of Aveiro) (Couto et al., 2013).

The fire resistance of cold-formed steel lipped channel columns is obtained using the software SAFIR (developed at the University of Liège) (Franssen, 2005). This software applies the finite element method (FEM) for geometric and material non-linear analysis. Being especially developed for the study of structures under fire situations, it has been applied in several research studies, as an example in studies on the evaluation of local buckling at elevated temperatures including validation with experimental tests (Couto et al., 2015), or numerical comparisons with other software (Prachar et al, 2014).

\section{CASE STUDY AND MODEL DESCRIPTION}

The present section describes the main parameters considered in this study and details the applied numerical models.

\subsection{Case study}

The main parameters that define the different models applied to perform the parametric study are here presented. Simply supported columns with different channel cross-sections slenderness and different steel grades were analysed (Table 1).

Table 1 Lipped channel cross-sections analysed.

\begin{tabular}{|c|c|c|c|c|c|c|}
\hline Designation & Web [mm] & Flange $[\mathrm{mm}]$ & Lip [mm] & Thickness $[\mathrm{mm}]$ & $f_{y}[\mathrm{MPa}]$ & $\theta\left({ }^{\circ} \mathrm{C}\right)$ \\
\hline C_229x64x20x(1.5)* & 229 & 64 & 20 & 1.5 & \multirow{4}{*}{$\begin{array}{l}320 \\
360\end{array}$} & \multirow{3}{*}{350} \\
\hline C_170x64x20x(1.5) & 170 & 64 & 20 & 1.5 & & \\
\hline C_229x48x20x(1.5) & 229 & 48 & 20 & 1.5 & & \\
\hline C_229x64x15x(1.5) & 229 & 64 & 15 & 1.5 & & \multirow{3}{*}{600} \\
\hline C_100x $50 \times 10 \times(1.6)^{* *}$ & 100 & 50 & 10 & 1.6 & \multirow[t]{2}{*}{460} & \\
\hline C_155x77x31x(2.0)**** & 155 & 77 & 31 & 2.0 & & \\
\hline
\end{tabular}

*(Schafer, 2006), **(Wang et al., 2006), ***(Batista, 1988)

Columns subjected to compression, for different high temperatures, were studied. For this research, the temperatures of $350{ }^{\circ} \mathrm{C}, 500{ }^{\circ} \mathrm{C}$ and $600{ }^{\circ} \mathrm{C}$ were adopted, $\left(350{ }^{\circ} \mathrm{C}\right.$ being the EC3 proposed critical temperature for thin-walled sections when no calculation is made; $500{ }^{\circ} \mathrm{C}$ and $600{ }^{\circ} \mathrm{C}$ being the most common critical temperature range in cold-formed steel elements). These were considered uniform throughout the cross-section, for an easier comparison with the design formulations proposed in EC3, and due to the reduced thickness of the walls' cross-section. The influence of the yield strength (320, $360,460 \mathrm{MPa}$ ) on ultimate strength of these elements was also analysed.

\section{$2.2 \quad$ Numerical model}

In the finite element model, rectangular shell finite elements were used to reproduce local buckling phenomena due to the walls' high slenderness. Loads in the parallel directions to the column axis were applied, along the whole section, according to the stresses distribution resulting from compression. The restraints were imposed in order to reproduce end pinned supports, one of them being a roller support. The numerical model with restraints and loads is presented in Figure 1.

The increased yield strength in the corners due to the cold-formed process was not considered, as it is also not considered in EC3 when buckling occurs. As the corner information was not the main concern of this study, membrane residual stresses were neglected, flexural residual stresses were modelled in all shell elements and the increased yield stress due to corners enhancement were not included (Schafer et al., 1998). 

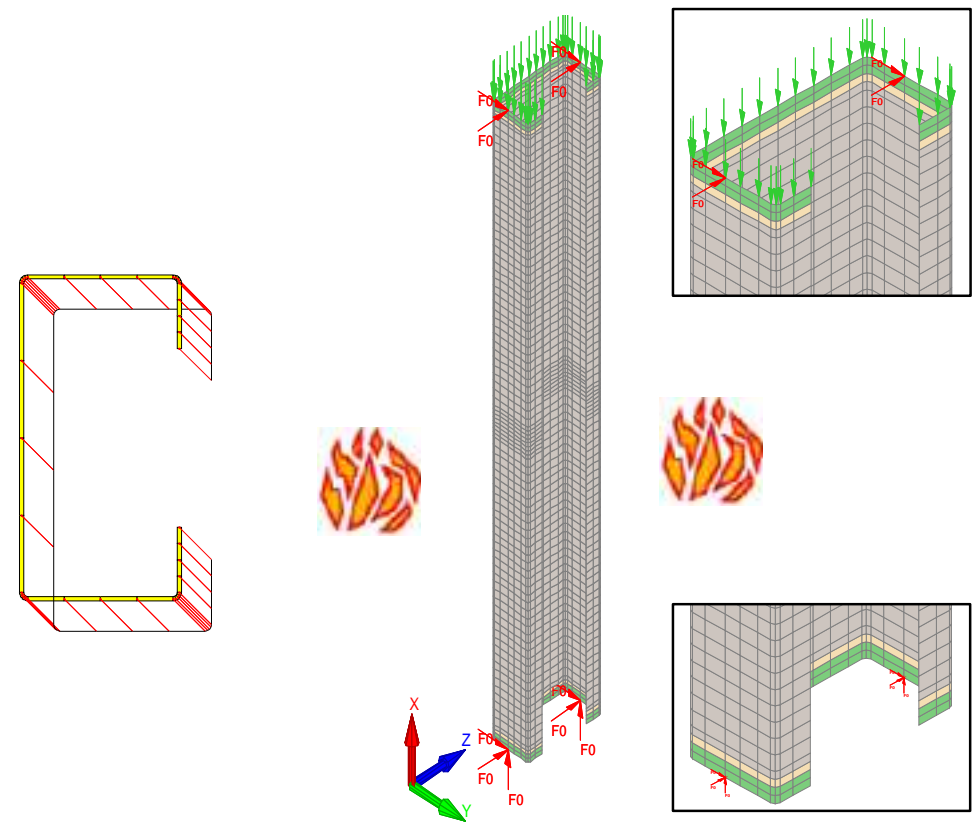

Fig. 1 Adopted numerical model for columns with lipped channel sections

The constitutive law applied is the one prescribed in Part 1-2 of EC3. However, the FN Annex of this same part of EC3 proposes the application of different stress-strain relationships for cold-formed profiles at elevated temperatures. These new material laws are obtained from different reduction factors for the yield strength and Young's modulus at high temperatures. The FN Annex proposes lower values for these reduction factors. Figure 2 illustrates the differences obtained for $500{ }^{\circ} \mathrm{C}$. As they are very different, both constitutive laws are also used in this study.

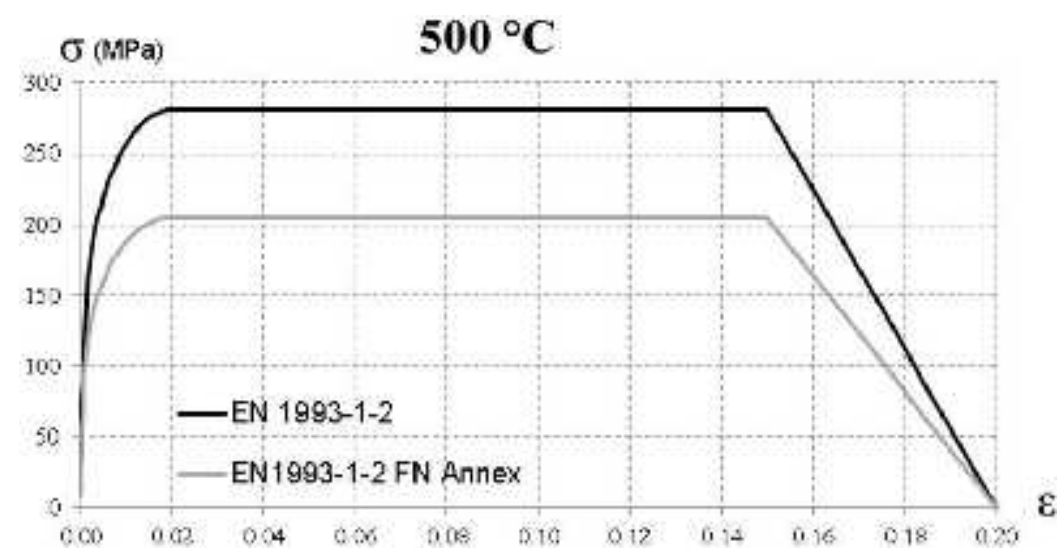

Fig. 2 Constitutive law for $500{ }^{\circ} \mathrm{C}$ according to EC3

Residual stresses are considered, due to press-braking manufacturing process, which is the most common manufacturing process (Dubina et al., 2012). Also, geometric imperfections such as the local, distortional and global are taken into account in these models analysis. The characterization of the influence of initial imperfections on the fire resistance has been studied in previous works (Lopes et al., 2013).

As mentioned before, to generate the initial geometric imperfections, different shapes based on the local, distortional and global buckling modes are used (Figure 3). For that purpose CAST3M and RUBY are applied. To consider these imperfections on numerical models Table 2 shows the maximum magnitude for the three buckling modes imperfection applied, where $b$ is the height of the web or width of the flange, whichever presents the larger deflection, and $\mathrm{L}$ the column length. The values given in Table 2 correspond to $80 \%$ of geometric fabrication tolerances, following the recommendations from Annex C of Part 1-5 of EC3 (CEN, 2006b), and described in section D.1 from Annex D of EN 10902+A1 (CEN, 2008). 
Table 2 Geometric imperfections magnitude

\begin{tabular}{|c|c|c|}
\hline Local & Distortional & Global \\
\hline $0,8 \times \frac{b}{100}$ & $0,8 \times \frac{b}{100}$ & $0,8 \times \frac{L}{750}$ \\
\hline
\end{tabular}

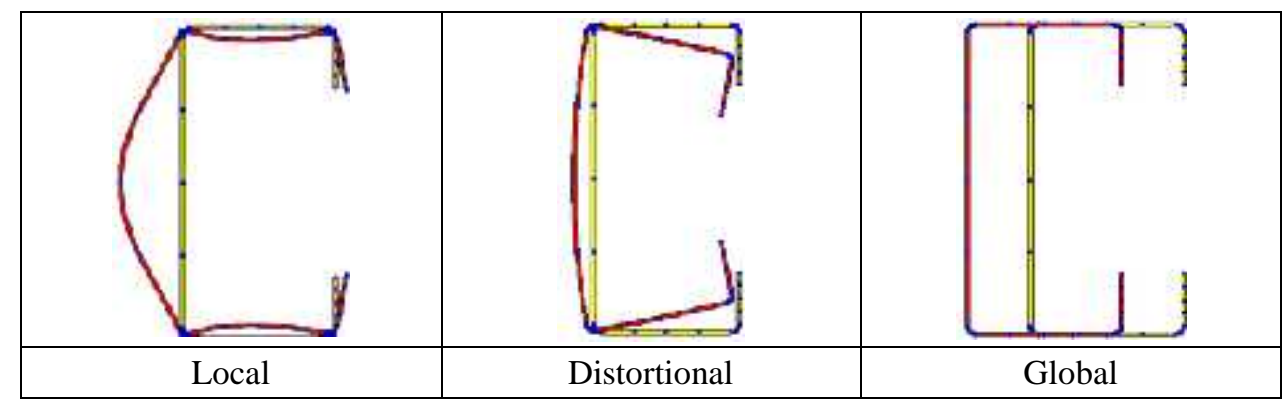

Fig. 3 Shapes of the considered geometric initial imperfections

Following the recommendations of Part 1-5 from EC3, the combined geometric imperfections are introduced. This part of EC3 states that in combining imperfections, a leading imperfection should be chosen and the accompanying imperfections may have their value reduced to $70 \%$. The leading imperfection is chosen in function of the achieved lower resistances.

\section{DISCUSSION ON THE RESULTS}

In this section, the influence of the cross-section slenderness, steel grade and temperatures on the ultimate load bearing capacity, of steel columns with cold-formed lipped channel sections, is analysed and compared with the simple calculation rules prescribed in Part 1-2 of EC3, considering Annex E and the FN Annex parameters.

The charts here presented do not represent the buckling curves since it is a case of combination of compression plus bending in the weak axis (caused by eccentrically load applied due to effective crosssection). Therefore the charts presents the $\mathrm{R}_{\mathrm{SAFIR}}$ which represents the value calculated applying the Eq. 4.21 from Part 1-2 of EC3, where $\mathrm{M}_{\mathrm{fi}, \mathrm{Ed}}=\mathrm{N}_{\mathrm{fi}, \mathrm{Ed}} \mathrm{X} e$, considering $\mathrm{N}_{\mathrm{fi}, \mathrm{Ed}}$ the value numerically obtained by SAFIR software, being $e$ the eccentricity between the real centre of gravity and the centre of the effective cross-section.

\subsection{Influence of the cross-section slenderness}

To study the influence of the different cross-section slenderness, six cross-sections with different dimension values are chosen. Each one is analysed for the yield strength equal to $360 \mathrm{MPa}$. Comparing the numerical results with the EC3 it is possible to conclude that the obtained values are on the safe side and the Eurocode curves sometimes too conservative. Due to the space limitation only few examples are presented. Observing Figure 4 a) and b), for more slender cross-sections the Eurocode curve is slightly more conservative.

Comparing Figure 4 a) and d), the results obtained applying the FN Annex constitutive law are closer to EC3 rules than the Annex E constitutive law, being the first on the unsafe side for high slenderness (Figure $4 \mathrm{~d}$ ).

\subsection{Influence of the steel grade}

Using one of the cross-sections, it was possible to analyse the influence of the steel grade varying the yield strength, using the 320, 360 and $460 \mathrm{MPa}$ values.

In Figure 4 a) and c) are presented the results for 360 and $460 \mathrm{MPa}$ and it is possible to observe, comparing the numerical results with EC3 rules, that the results are again on the safe side and the influence of the steel grade is important. Also considering Figure 4 a) and c) results, it is possible to conclude that increasing the yield strength the Eurocode curve is less conservative. 


\subsection{Influence of the temperature}

For each analysis it is considered different high temperatures as mentioned before, for $350{ }^{\circ} \mathrm{C}, 500{ }^{\circ} \mathrm{C}$ and $600{ }^{\circ} \mathrm{C}$. Analysing Figure 4, the obtained normalized results do not present a significant different behaviour in function of the temperature.

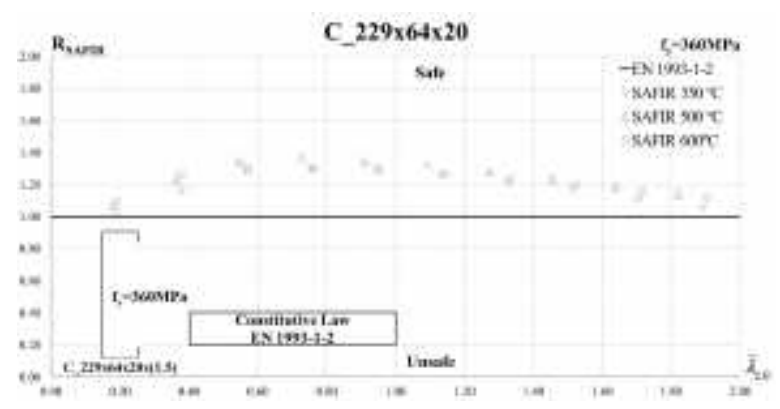

a) C_229x64x20, Annex E $\left(f_{y}=360 \mathrm{MPa}\right)$

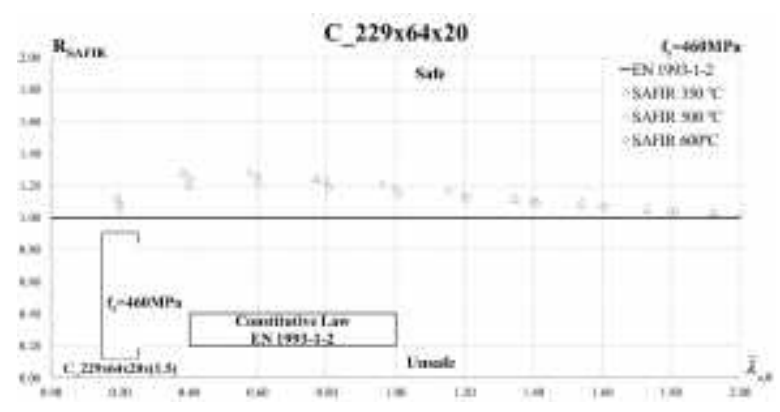

c) C_229x64x20, Annex E $\left(f_{y}=460 \mathrm{MPa}\right)$

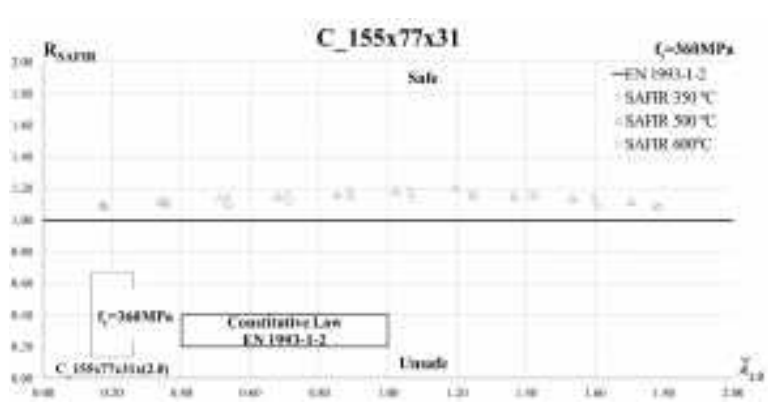

b) C__ $155 \times 77 \times 31$, Annex E $\left(f_{y}=360 \mathrm{MPa}\right)$

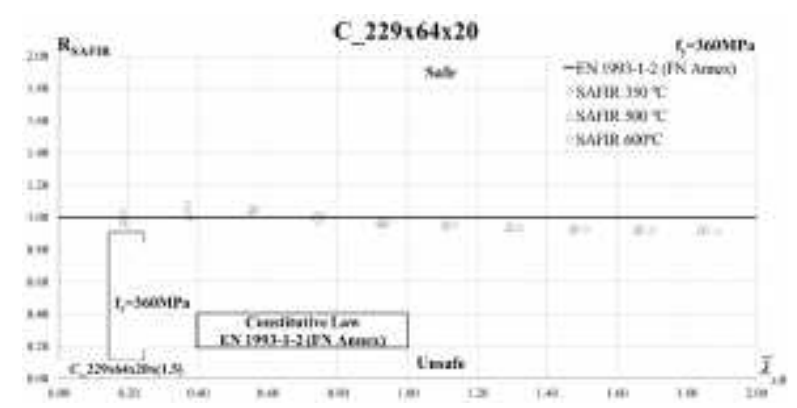

d) C_229x64x20, FN Annex $\left(f_{y}=360 \mathrm{MPa}\right)$

Fig. 4 Comparison of the results obtained with SAFIR and the Eurocode rules

According to the values presented on Table 3 and Figure 4, it is possible to observe that the EN 1993-12 FN Annex is less conservative than the current EN 1993-1-2 considering the Annex E values, but not as safe.

Table 3 Statistical evaluation for lipped channel cross-sections at elevated temperatures

\begin{tabular}{|c|c|c|}
\hline Design rule & Average value ( ) & Standard deviation (s) \\
\hline EN 1993-1-2 (Annex E) & 0.8594 & 0.0634 \\
\hline EN 1993-1-2 (FN Annex) & 1.0321 & 0.0484 \\
\hline
\end{tabular}

\section{CONCLUSIONS}

In this work it is presented a parametric study of the buckling behaviour of simply supported members with cold-formed lipped channel sections (C), in case of fire, when subjected to compression. The influence of the different cross-section slenderness, steel grades and high temperatures is evaluated.

A comparison between the ultimate loads and formulae prescribed in EC3 is performed, concluding that the current calculation rules are on the safe side and are sometimes too conservative. It is possible to observe that applying the Annex E design rules is more conservative than applying the FN Annex, having the latter showed a good agreement with the numerical results but some unsafe results.

It is possible to conclude that it is necessary a deeper analysis on the influence of the different crosssection slenderness. Increasing the yield strength the results are less conservative. And the numerical results do not present different behaviour in function of the temperature.

New proposals for the design of cold-formed steel columns must be developed in order to introduce minimum changes in the existing formulae and providing at the same time safety and accuracy when compared to the numerical results. 


\section{ACKNOWLEDGMENTS}

This research work was partially funded by the Portuguese Government through the FCT (Foundation for Science and Technology) under the PhD grant SFRH/BD/90455/2012 (POPH/FSE funding) awarded to the first author.

\section{REFERENCES}

Arrais F., 2012. Comportamento de elementos enformados a frio em situação de incêndio, Master Thesis, University of Aveiro, Portugal (in Portuguese).

ASRO, 2008. Introduction to cold-formed steel design, Technical document ICS 91.010.30;91.080.10.

Batista B. M., 1988. Etude de la stabilité des profiles a parois minces et section ouverte de types $U$ et $C$, Faculté des Sciences Appliquées no. 119, University of Liége, Belgium.

Camotim D., Gonçalves R., 2007. Thin-walled member plastic bifurcation analysis using generalised beam theory. Advances in Engineering Software, 38, p. 637-646.

CAST3M, 2012. Development sponsored by French Atomic Energy Commission, <http://wwwcast3m.cea.fr/>.

CEN, 2005. EN 1993-1-2, Eurocode 3: Design of Steel Structures - Part 1-2: General rules - Structural fire design, Brussels, Belgium.

CEN, 2006b. EN 1993-1-5, Eurocode 3: Design of Steel Structures - Part 1-5: Plated structural elements, Brussels, Belgium.

CEN, 2007. NF EN 1993-1-2, Eurocode 3: Calcul des structures en acier - Annexe Nationale à la NF EN 1993-1-2: Calcul du comportment au feu, Brussels, Belgium.

CEN, 2008. EN 1090-2+A1, Execution of steel structures and aluminium structures - Part 2: Technical requirements for steel structures, Brussels, Belgium.

Couto C., Vila Real P., Lopes N., 2013. RUBY an interface software for running a buckling analysis of SAFIR models using CAST3M, University of Aveiro, Portugal.

Couto C., Vila Real P., Lopes N., Zhao B., 2015. Resistance of steel cross-sections with local buckling at elevated temperatures. Journal of Constructional Steel Research, 109, p. 101-114.

Dubina D., Ungureanu V., Landolfo R. 2012. Design of Cold-formed Steel Structures. Eurocode 3: Design of Steel Structures. Part 1-3: Design of Cold-formed Steel Structures, ECCS.

Franssen J. M., 2005. SAFIR. A Thermal/Structural Program Modelling Structures under Fire. Engineering Journal, A.I.S.C., 42(3), p. 143-158.

Gunalan S., Heva Y., Mahendran M. 2015. Local buckling studies of cold-formed steel compression members at elevated temperatures. Journal of Constructional Steel Research, 108, p. 31-45.

Laim L., 2013. Experimental and Numerical Analysis of the Behaviour of Cold Formed Steel Elements in Fire, $\mathrm{PhD}$ Thesis, University of Coimbra, Portugal (in English).

Lopes N., Arrais F., Vila Real P., 2013. Fire resistance of cold-formed C steel columns, in Applications of Structural Fire Engineering - ASFE, Prague, Czech Republic, p. 244-250.

Prachar M., Lopes N., Couto C., Jandera M., Vila Real P., Wald F., 2014. Lateral torsional buckling of class 4 steel plate girders under fire conditions: experimental and numerical comparison. COST Action TU0904 - Experimental validation of numerical models in fire engineering, Prague, p. 21-33.

Schafer B. W., 2006. Designing Cold-Formed Steel Using the Direct Strength Method, in 18th Int. Specialty Conference on Cold-Formed Steel Structures, Orlando, Florida, USA.

Schafer B. W., Peköz T., 1998. Computational modeling of cold-formed steel: characterizing geometric imperfections and residual stresses. Journal of Constructional Steel Research, 47, p. 193-210.

Schafer B. W., Ádány S., 2006. Buckling analysis of cold-formed steel members using CUFSM: conventional and constrained finite strip methods, in 18th Int. Specialty Conference on Cold-Formed Steel Structures, Orlando, Florida, USA.

Shahbazian A., Wang Y. C., 2011. Calculating the global buckling resistance of thin-walled steel members with uniform and non-uniform elevated temperatures under axial compression. Thin-Walled Structures, 49 (11), p. 1415-1428.

Silvestre N., Camotim D., 2010a. Construção em aço leve, Journal of CMM - Associação Portuguesa de Construção Metálica e Mista, 20.

Silvestre N., Camotim D., 2010b. On the mechanics of distortion in thin-walled open sections. Thin-Walled Structures, 48(7), p. 469-481.

Wang X. P., Lam S. S. E., Chung K. F., 2006. Cross section distortion due to cutting of cold-formed steel lipped C-section. Thin-Walled Structures, 44(3), p. 271-280. 